\title{
Stability of a Roadway below a Coal Seam under Dynamic Pressure: A Case Study of the 1123 Floor Gas Drainage Roadway of a Mine in Huainan, China
}

\author{
Pingsong Zhang, ${ }^{1,2}$ Yuanchao Ou $\mathbb{D}^{1,2}$ Chang Liu, ${ }^{1,2}$ Binyang Sun, ${ }^{1,2}$ and Chong $\mathrm{Xu}^{3}$ \\ ${ }^{1}$ State Key Laboratory of Mining Response and Disaster Prevention and Control in Deep Coal Mines, \\ Anhui University of Science and Technology, Huainan 232001, China \\ ${ }^{2}$ School of Earth and Environment, Anhui University of Science and Technology, Huainan 232001, China \\ ${ }^{3}$ Ping'an Coal Mining Institute of Engineering Technology Co., Ltd., Huainan 232001, China \\ Correspondence should be addressed to Yuanchao Ou; ycou623@163.com
}

Received 9 November 2019; Revised 16 November 2020; Accepted 23 November 2020; Published 9 December 2020

Academic Editor: Raghvendra Kumar

Copyright (c) 2020 Pingsong Zhang et al. This is an open access article distributed under the Creative Commons Attribution License, which permits unrestricted use, distribution, and reproduction in any medium, provided the original work is properly cited.

\begin{abstract}
Coal and gas outburst is an important risk faced by coal seam mining in the Huainan region of China. In order to control gas outburst, the gas is predrained by digging a floor gas drainage roadway. To study deformation due to dynamic pressure, the failure characteristics of the floor, and their effect on the stability of the floor gas drainage roadway, a comprehensive monitoring method combining Brillouin optical time-domain reflectometry- (BOTDR-) distributed fiber optics and self-potential exploration was adopted. Dynamic data monitoring of the rock strata between the 11123 working face floor and the floor gas drainage roadway of a mine in Huainan was carried out. The field data obtained showed that, when stabilized by rock bolts and other fixed components in the surrounding rock mass of the floor gas drainage roadway, under the influence of mining, the area of concentrated stress appeared at a depth of $20.7 \mathrm{~m}$, when cracks eventually formed, but the overall structural stability of the surrounding rock mass remained good. The stress distribution and crack evolution of the bottom plate under the influence of dynamic pressure showed spatiotemporal characteristics. Of these, the effect of the lead support stress was $107.48 \mathrm{~m}$, and the range of effect of the hysteresis stress was $34.42 \mathrm{~m}$. When the working face mining position arrives and is far from the monitoring station, the failure depth of floor rock stratum shows the following rule: unchanged in the early stage, deepened continuously in the middle stage, and finally remained stable. It takes about eight days for the dynamic adjustment of this process to finally stabilize. The results of this study can provide guidance for devising suitable procedures for carrying out intelligent green safety mining and for warning about the hazards of roadway damage.
\end{abstract}

\section{Introduction}

In coal and gas outburst mining areas [1], such as those surrounding the city of Huainan, in north-central Anhui Province, China, it is often necessary to design suitable floor gas drainage roadways [2] in advance, at a certain depth below the working face, and to carry out safety work related to equipment system layouts, such as coal seam gas extraction and ventilation. In the later stages of mining operations, once the working face has been mined, the original state of stress balance of the surrounding rock will be altered. The transfer of mining stress to the floor rock mass will eventually lead to the deformation and destruction of rock strata within a certain depth of the floor. At that time, if the floor gas drainage roadway is located in the affected area and the on-site support conditions are insufficient, this will inevitably lead to the instability of the surrounding rock and of the floor gas drainage roadway and even render the operation of the roadway equipment system unsafe [3-5]. For these reasons, we chose to study and determine the characteristics of floor failure under the influence of dynamic pressure and the effect on the stability of the rock surrounding the floor gas drainage roadway. The results obtained in this study will be of great practical importance 
for safe and stable mining and for the support of roadways under coal seam working faces in areas such as Huainan and other high gas-rich mining areas.

In recent years, researchers in China and abroad have carried out numerous studies of the damage and characteristics of the floor under the influence of mining [6-12]. Song et al. [13] set up a mechanics calculation model of the floor along the inclination of the working face against the background of confined water mining in the 41503 working face of a mine and derived, theoretically, the stress distribution and failure characteristics of the floor. Zhang et al. [14] used seismic computed tomography (CT) detection technology to dynamically monitor the deformation and failure of a floor during coal mining. Zhang et al. [15] used the mutual verification method involving the field strain test as well as numerical simulations to comprehensively study the damage depth of a thick mined coal seam. By sorting and analyzing a large quantity of field-measured data, Zhu et al. [16] explored the different deformations and failure characteristics of different lithologies and composite floor structures under the influence of dynamic pressure.

There are also abundant research results relating to the deformation and failure characteristics of rock structures surrounding roadways [17-24]. Li et al. [25] used a numerical simulation method to study the mechanism of roadway failure caused by repeated caving in the Huaibei mining area and proposed a new supporting scheme. Chen et al. [26] used the true triaxial analog simulation method to study the characteristics of strain evolution and fracture of the rock surrounding a mining roadway under the gradient loading of dynamic pressure. Hua and Yang [27] used a Brillouin optical time-domain analysis- (BOTDA-) distributed fiber optical sensor (DFOS) and close-range photographic technology to monitor the deformation of the roadway floor during the process of gob-side entry retaining (GSER) excavation, first mining, retaining lane, and secondary mining. The dynamic evolution characteristics of the deformation of the floor of the GSER with a large cross section in a deep mine were obtained. Li et al. [28] used a high-precision microseismic monitoring system and a roof dynamic monitoring instrument to delineate the floor failure depth of the 2200 working face and also studied the deformation and failure mechanism of the 4106 material roadway and transportation roadway below the working face.

Based on the above research results, this study took the 11123 working face and the 11123 floor gas drainage roadway of a mine in Huainan as an engineering case study. Using the integrated monitoring method that combines Brillouin optical time-domain reflectometry (BOTDR)DFOS and self-potential exploration, whole-process dynamic data monitoring was conducted. The failure characteristics of the 11123 working face floor were determined, and the stability of the rock surrounding the 11123 floor gas drainage roadway under the influence of dynamic pressure was studied.

The main contributions of this paper include the following: (1) a comprehensive monitoring technology consisting of distributed strain fiber optics and spontaneous potential tests was used to monitor the stability of the surrounding rock under dynamic pressure, which overcame the problems of single-test means and the small quantity of measured data obtained in previous studies. The results obtained by comprehensive monitoring data are self-verifying, which improves the reliability of the data; (2) the response characteristics of the multiphysical field data and the changes in the stability of the surrounding rock under dynamic pressure were obtained, which will aid future studies on the stability of the rock surrounding a roadway; (3) it was found that the failure depth of floor strata lags behind the secondary deepening of the coal wall under the action of mining. According to the spatiotemporal evolution characteristics of floor fracture, the characteristics of and time required from the moment of dynamic adjustment to the formation of a stable stage were determined.

\section{Engineering Geological Conditions}

The 11123 working face of the mine is located in the Huainan region, and the working face elevation was, at the time of the study, in the range from -450 to $-490 \mathrm{~m}$ (working face 11123 belongs to the \#3 coal seam). The average buried depth of the working face was approximately $470 \mathrm{~m}$, the mining strike length of the working face was approximately $1345 \mathrm{~m}$, and the inclined length was $155 \mathrm{~m}$. The average thickness of the coal seam was $5.5 \mathrm{~m}$, and the average dip angle of the coal seam was $10^{\circ}$. The \#3 and \#1 coal seams were both gas outburst seams. The gas content of the \#3 coal seam was $6.6-7.7 \mathrm{~m}^{3} / \mathrm{t}$, the gas pressure was $1.76-2.44 \mathrm{MPa}$, the gas content of the \#1 coal seam was $5.2-6.5 \mathrm{~m}^{3} / \mathrm{t}$, and the gas pressure was $1.35-2.08 \mathrm{MPa}$. In the early stages of mining, gas pre-extraction treatment was carried out for the \#3 and \#1 coal seams at the same time. After the standard of gas extraction was reached, mining operations on the \#3 coal seam were carried out. Roof management was strengthened during the initial caving stage, and gas management and ventilation were strengthened during the mining process to prevent gas from being trapped in the sandstone layer and causing the gas to exceed the standard safety limit.

The 11123 working face was mined to a thickness of approximately $5 \mathrm{~m}$. There were no large faults or structures in the working face. The lithology and other related information of the \#3 coal seam are shown in Figure 1. The 11123 floor gas drainage roadway was located in (8) fine sandstone and (9) sandy mudstone, with a width $\times$ height of $4600 \mathrm{~mm} \times 3500 \mathrm{~mm}$. The top and bottom rock layers consisted of hard and dense limestone. The roadway was used mainly for the placing and installation of safety equipment and systems for gas drainage and ventilation.

The support scheme of the 11123 floor gas drainage roadway adopts the support form of "bolt + anchor net + local anchor cable and grouting". Some fractured or weak surrounding rock sections are strengthened in advance. The anchor is a strong pretensioned anchor, the anchor is $\Phi 20 * 2500 \mathrm{~mm}$, the spacing is $700 \times 700 \mathrm{~mm}$, the anchor cable is $\Phi 21.8 * 6500 \mathrm{~mm}$, and the spacing is $1900 \times 2000 \mathrm{~mm}$. Three anchor cables are designed 


\begin{tabular}{|c|c|c|c|}
\hline $\begin{array}{c}\text { Serial } \\
\text { number }\end{array}$ & $\begin{array}{c}\text { Strate } \\
\text { thickness } \\
(\mathrm{m})\end{array}$ & Columnar & Lithology name \\
\hline (1) & 5.5 & & 3 Coal seam \\
\hline (2) & 1.5 & $-\quad=$ & Mudstone \\
\hline (3) & 3.5 & & 1 coal seam \\
\hline (4) & 3.8 & \begin{tabular}{|l|}
$-\cdot-$ \\
$-\cdot \cdot$ \\
$\cdot-\cdot$ \\
$-\cdot$
\end{tabular} & Sandy mudstone \\
\hline (5) & 4.2 & \begin{tabular}{cc|} 
& $\ldots$ \\
$\cdots$ & \\
$\ldots$ & $\ldots$ \\
$\ldots$ & $\ldots$ \\
$\ldots$ & $\ldots$
\end{tabular} & Fine sanddtone \\
\hline \multirow[t]{2}{*}{ (6) } & \multirow[t]{2}{*}{9.0} & 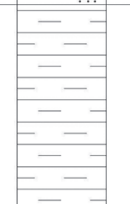 & Mudstone \\
\hline & & $\begin{array}{l}- \\
- \\
-- \\
-\end{array}$ & Limestone \\
\hline (7) & 1.2 & \begin{tabular}{|c|}
$T$ \\
$T$ \\
$T$
\end{tabular} & Fine sandstone \\
\hline (8) & 2.0 & $\ldots$ & \\
\hline (9) & 1.5 & \begin{tabular}{|l|}
$\cdot-\cdot$ \\
$-\cdot-$ \\
\end{tabular} & Sandy mudstone \\
\hline (10) & 2.5 & \begin{tabular}{|l|l|l|} 
& 1 & 1 \\
& 1 & 1 \\
& 1 & 1 \\
& 1 & 1 \\
\end{tabular} & Limestone \\
\hline
\end{tabular}

Figure 1: Comprehensive column map of strata.

symmetrically in each roadway section according to the central axis; the spray layer adopts C20 concrete with a thickness of $100 \mathrm{~mm}$ (Figure 2).

\section{Integrated Monitoring Scheme}

3.1. Distributed Fiber Optical Strain Monitoring Technology. During the monitoring period, an AV6419-distributed optical fiber tester was used for on-site data acquisition. The instrument realizes single-end measurements without a double-end closed loop, which was very convenient and meets the complex conditions of underground construction, layout, and data acquisition.

When the fiber attached to the surface (or inside) of the target is stretched or squeezed due to the deformation and failure of the target, the frequency of the Brillouin backscattered light reflected by the fiber in the strain region will change. The distributed optical fiber tester will measure the received Brillouin backscattered light power

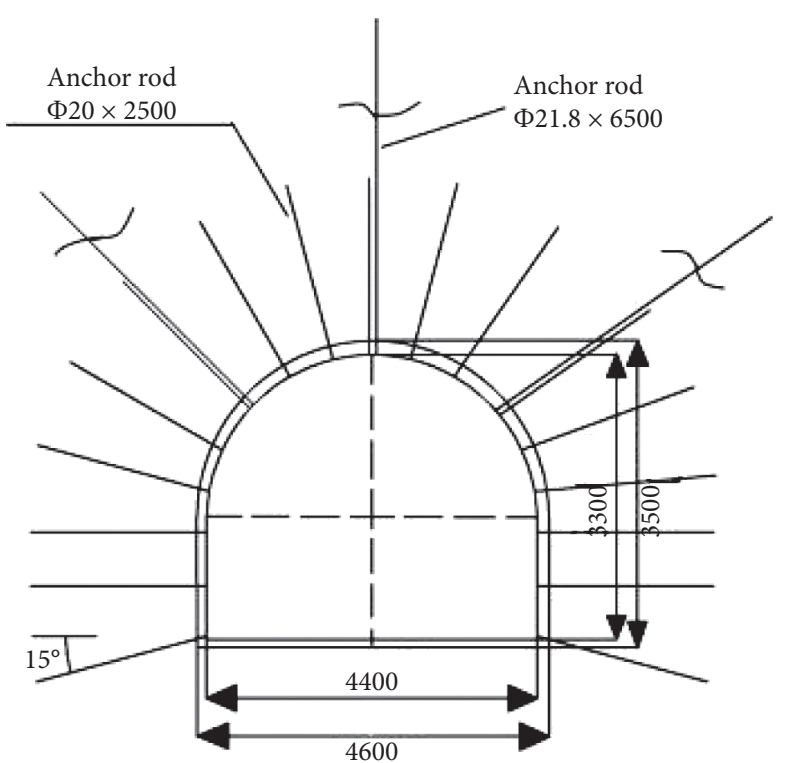

FIGURE 2: Cross-section design of the supporting scheme of 11123 floor gas drainage roadway.

and then obtain the Brillouin frequency shift of each point on the optical fiber. Finally, according to the linear relationship between the Brillouin frequency shift and strain, the strain distribution of each part of the target body was obtained. When the temperature of the target body changes by only a small amount during the monitoring period, the strain value of each point along the optical fiber can be calculated by the following formula:

$$
v_{B}(\varepsilon)=v_{B}(0)+\frac{\mathrm{d} v_{B}(\varepsilon)}{\mathrm{d} \varepsilon} \varepsilon
$$

where $\varepsilon$ is the strain value, $v_{B}(\varepsilon)$ is the Brillouin optical frequency shift when the strain is $\varepsilon, v_{B}(0)$ is the Brillouin frequency shift in the original state, and $\mathrm{d} v_{B}(\varepsilon) / \mathrm{d}(\varepsilon)$ is the proportional coefficient, which is about $493 \mathrm{MHz}$.

Some scholars [29-32] in China have introduced this technology underground to study the deformation and damage of the roof and the surrounding rock in the mining process, and the test accuracy and data volume are better than the conventional testing methods.

3.2. Self-Potential Monitoring Technology. The data of the geoelectric field during the monitoring period were tested dynamically by the network parallel electrical instrument [33], and the data of the self-potential change in the monitoring section during the mining process of the working face were obtained completely.

In the absence of an artificial power supply to the geological body, the potential difference between any two points can be observed by the instrument, indicating that there was a natural electric field (self-potential field) inside the geological body. However, the self-potential field in the geological body will change dynamically due to the influence of groundwater flow and rock mass deformation and damage. It is believed that these effects will change the 
stability of the original charge structure inside the rock mass and its distribution in space, accompanied by the separation, movement, and aggregation of the charge at different positions of the rock mass and then form the dynamic change of the self-potential field $[34,35]$.

3.3. System Construction. To understand the damage depth of the 11123 working face under the influence of dynamic pressure and its stability in relation to the lower floor gas drainage roadway, site drilling was designed in the middle of the (8) fine sandstone rock layers on the sidewall of the floor gas drainage roadway and inclined upwards to the initial mining position of the working face (Figure 3 and Table 1).

Additionally, after the fiber optic cable and electric cable were implanted into the hole to a predetermined depth by means of the auxiliary tools, layered grouting was carried out in the hole and allowed to set there for a period of time (Figure 4 and Table 2). Each cable was then allowed to fully couple and solidify in contact with the slurry and the surrounding rock mass, and, once the slurry had reached the desired strength, data acquisition began on-site.

\section{Results and Analysis of Field Data}

4.1. Field Data Collection. On-site monitoring took place from October 31, 2018, to February 25, 2019. The field data were obtained during the entire monitoring period for a total of 57 times and were of good quality.

According to the information provided by the mine during the monitoring period and the observations of the on-site personnel, there were no water leakages in the working face and floor gas drainage roadway during the entire monitoring period. We consider that the data collected at the site were not disturbed by any seepage field, such as groundwater. Because of the working shift of the coal mining team and the interference due to the industrial electric field, we chose to collect the field data at 2 p.m. each day.

\subsection{Characteristics of Floor Failure and Stability of the Surrounding Rock in the Floor Gas Drainage Roadway}

4.2.1. DFOS Monitoring Results. We selected 12 groups of fiber optic strain data for processing during the monitoring period and obtained the corresponding relationship between the fiber optic strain distribution and the stratum (Table 3 and Figure 5). The cloud diagram of the fiber optical strain distribution during monitoring is shown in Figure 6. Figure 7 shows the cross section of the corresponding relationship between the support structure of the floor gas drainage roadway and the stratum.

On October 31, 2018, the working face was still in the nonmining stage, and at this time, the original stress state of the surrounding rock had not changed. On November 12, 2018, the fiber optic data changed for the first time, and the corresponding strain values were +416 and $+347 \mu \varepsilon$ (areas I and II). From the analysis of the stable composite rock beam structure formed by the action of the anchor bolts and the other fixed components in the surrounding rock of the floor gas drainage roadway, it is considered that the stress distribution of the floor gas drainage roadway and its surrounding rock mass under the mining position was changed by the mining process on the working face. But, because the floor gas drainage roadway and its surrounding rock mass were strongly supported by anchoring, etc., they assumed a combination of high-strength and damage-resistant characteristics, which made the rock mass surrounding the floor gas drainage roadway better able to transmit stress than the other layers, over a greater distance, and with a greater bearing capacity. On November 21, 2018, the tensile strain values reached +3306 and $+1003 \mu \varepsilon$ (areas I and II), indicating that an area of concentrated stress had been formed in the rock mass beyond the control range of the anchor bolts above the floor gas drainage roadway. At the same time, the internal stress of the (4) sandy mudstone layer (area III) changed for the first time, and the tensile strain reached $+517 \mu \varepsilon$. This analysis shows that the mining lead stress of the working face was transmitted to the monitoring area through the (4) sandy mudstone layer under the mining position.

As the working face advanced continuously and gradually came closer to the monitoring section, the change in stress of the bottom slate layer affected by mining gradually increased. On December 12, 2018, the maximum strain values reached +8149 and $+2574 \mu \varepsilon$ (areas I and II) and the strain value of the (4) sandy mudstone layer increased to $+1823 \mu \varepsilon$ (area III). The internal stress of (5) fine sandstone changed rapidly to $+1005 \mu \varepsilon$ (area IV). According to the analysis, the effect of the leading stress of the working face mining position on the rock mass in the monitoring area increased, and microcracks gradually emerged in the rock mass. On December 22, 2018, the working face mining position had just crossed the top of the monitoring hole at $5.9 \mathrm{~m}$. During this process, the changes in strain of areas V and IV were the most obvious, increasing by 1173 and $1755 \mu \varepsilon$, respectively, which showed that the evolution of the floor crack under the influence of dynamic pressure had spatiotemporal effects. The tensile expansion of the floor in the goaf was obvious. The microcracks in areas III, V, and IV expanded further and joined together to produce macroscopic fractures. At the same time, the bottom drum expansion of the working surface was obvious. The rock mass in area I, with a significant concentration of stress, produced a separation crack, which was developed in the upper part of the control area of the anchor member (Figure 6). Although the degree of strain in area II of the surrounding rock of the roadway was large, it remained stable under the control of the bolt member and no damage occurred. Further analysis is carried out below in conjunction with the natural potential and electrode current data.

Between December 22, 2018, and January 12, 2019, the overlying rock mass of the goaf collapsed, and crushed and squeezed the floor rock mass. Areas III and V rapidly decreased and stabilized at $+601 \mu \varepsilon$; the strain value of area IV then decreased to $+1304 \mu \varepsilon$ and remained stable. From January 12, 2019, to February 25, 2019, the tensile strain in the mudstone layer in area I gradually decreased and finally 


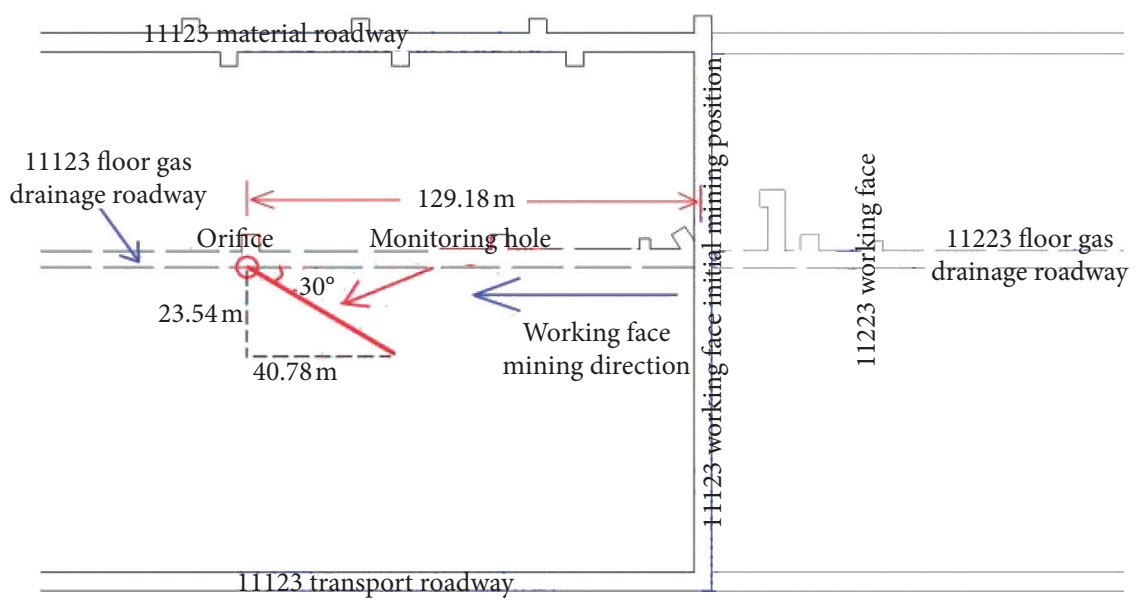

FIGURE 3: Plane layout sketch of the 11223 working face.

TABle 1: Design parameters of the monitoring hole in the 11123 floor gas drainage roadway.

\begin{tabular}{lccc}
\hline Technical parameter & Monitoring hole & Technical parameter & $\begin{array}{c}\text { Monitoring } \\
\text { hole }\end{array}$ \\
\hline $\begin{array}{l}\text { Angle with the roadway }\left({ }^{\circ}\right) \\
\begin{array}{l}\text { Distance between orifice and initial mining position } \\
(\mathrm{m})\end{array}\end{array}$ & 30 & Drilling elevation angle $\left(^{\circ}\right)$ & 20 \\
Actual hole length $(\mathrm{m})$ & 129.18 & Angle between borehole and inclined stratum $\left(^{\circ}\right)$ & 24 \\
\hline
\end{tabular}

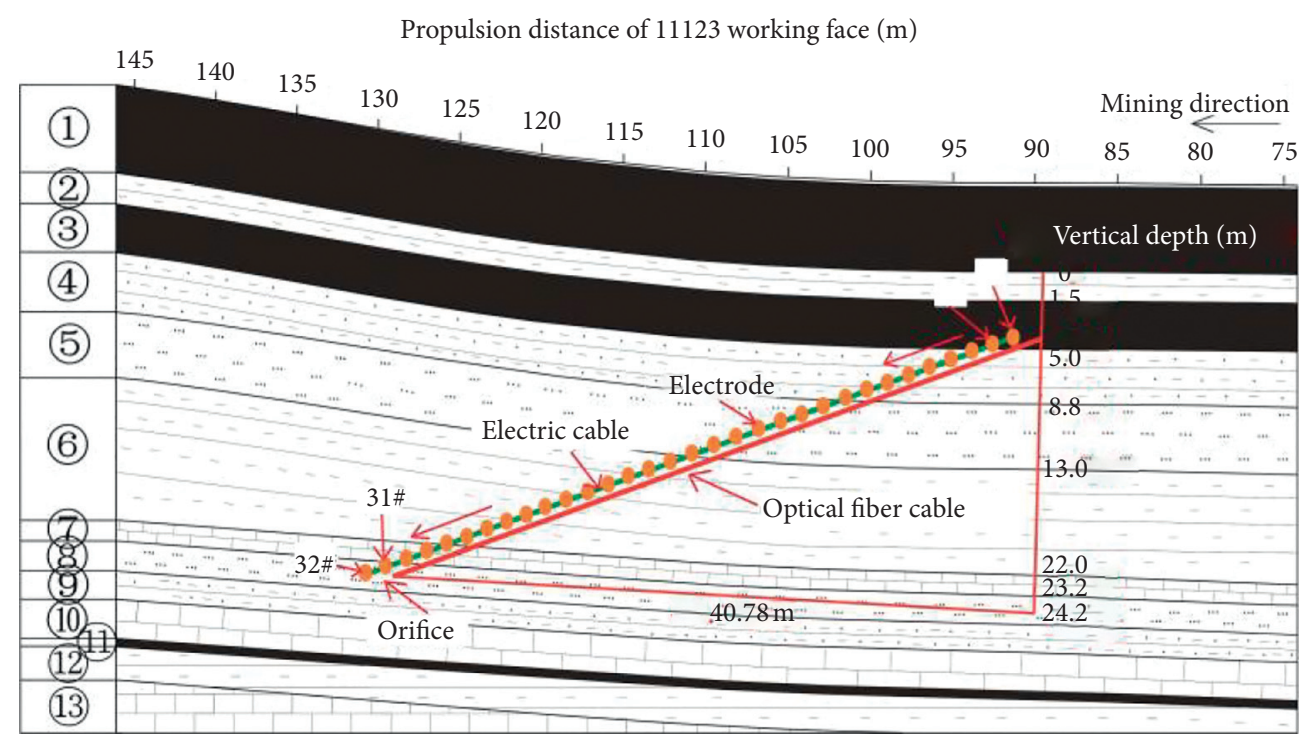

FIGURE 4: Schematic diagram of cable arrangement for the integrated monitoring system.

TABLE 2: Technical parameters of the integrated monitoring system.

\begin{tabular}{|c|c|c|c|}
\hline \multicolumn{2}{|c|}{ Distributed optical fiber monitoring system } & \multicolumn{2}{|c|}{ Self-potential monitoring system } \\
\hline Diameter of fiber optic cable (mm) & 5 & Number of electrodes & 32 \\
\hline Strain coefficient $(\mathrm{MHz} / \%)$ & 499.8 & Electrode space $(\mathrm{m})$ & 1.5 \\
\hline Maximum break force $(\mathrm{N})$ & 2350 & Effective length (m) & 46.2 \\
\hline Strain fiber optic cable type & High-strength metal-based fiber optic cable & Control vertical height $(\mathrm{m})$ & 18.79 \\
\hline Effective length $(\mathrm{m})$ & 46.2 & - & - \\
\hline Control vertical height $(\mathrm{m})$ & 18.79 & - & - \\
\hline
\end{tabular}

Electrode \#32, which should be placed outside the monitoring orifice, was also fixed inside the orifice. 
TABLE 3: Working face propulsion data record table.

\begin{tabular}{lcc}
\hline Date of collection & Working face mining length $(\mathrm{m})$ & Distance between mining location and orifice $(\mathrm{m})$ \\
\hline $2018-10-31$ & 0 & 129.18 \\
$11-12$ & 18.9 & 110.28 \\
$11-21$ & 38.3 & 90.88 \\
$12-02$ & 54.9 & 74.28 \\
$12-12$ & 78.7 & 50.48 \\
$12-22$ & 94.3 & 34.88 \\
$2019-1-02$ & 110.4 & 18.78 \\
$1-12$ & 122.1 & 7.08 \\
$1-21$ & 140.9 & -11.72 \\
$1-29$ & 153.8 & -24.62 \\
$2-18$ & 163.6 & -34.42 \\
$2-25$ & 178.1 & -48.92 \\
\hline
\end{tabular}
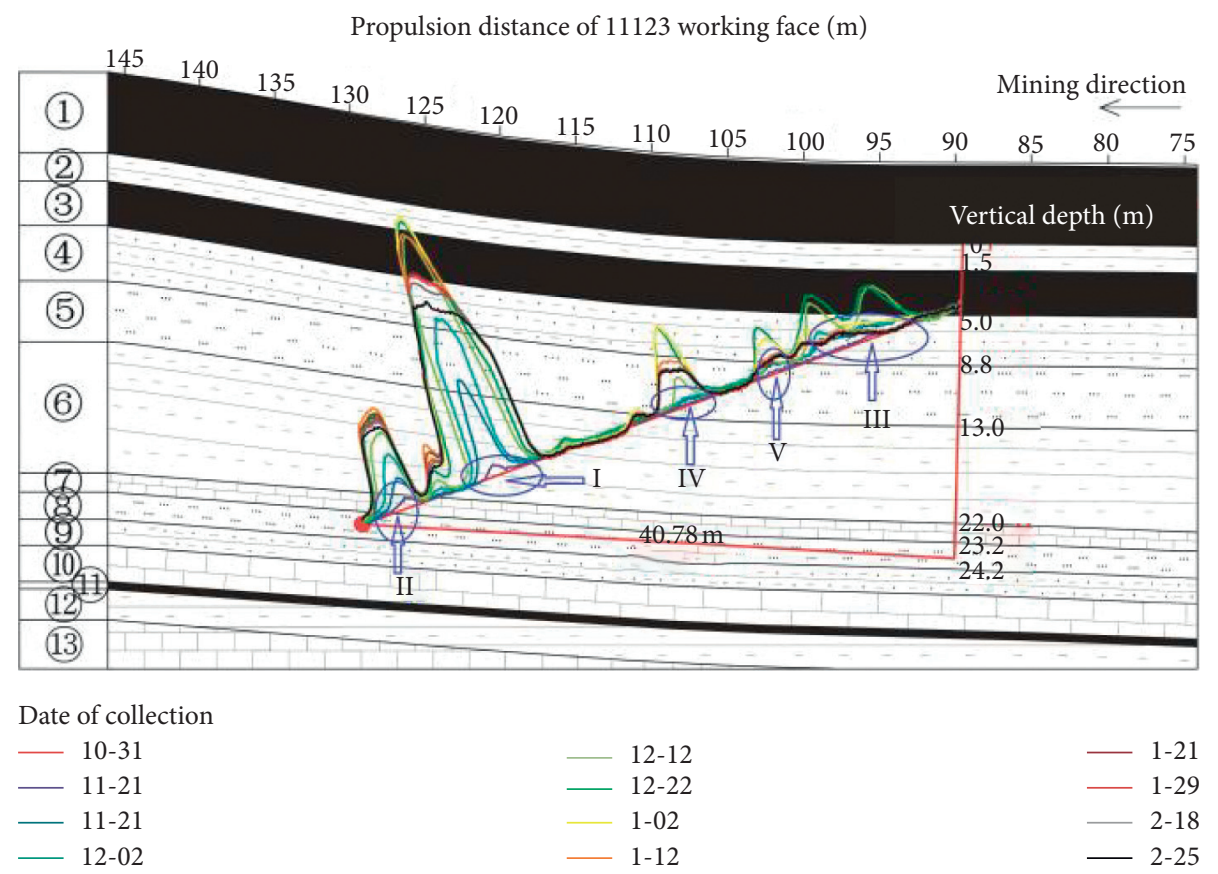

FIGURE 5: Corresponding relationship between strain distribution of the optical fibers and the stratum.

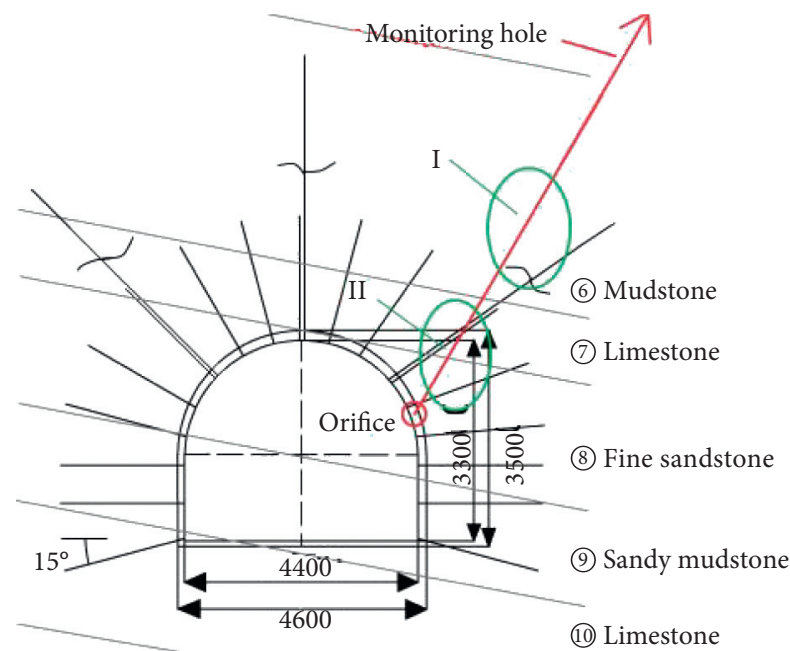

FIGURE 6: Sectional view of the corresponding relationship between the supporting structure of floor gas drainage roadway and the stratum. stabilized at $+5923 \mu \varepsilon$. In this process, the internal strain in the rock layer controlled by the anchor rod changed little and remained at $+2844 \mu \varepsilon$. During this period, the stress in the rock mass under the influence of mining continued to adjust dynamically and finally formed a new stress equilibrium state.

Next, we analyzed the process of deformation and failure during the entire monitoring period through the fiber optic strain nephogram (Figure 7). From this, it can be seen that the strain value of area I (the vertical depth was 19.5-20.5 m) was larger than that of the other vertical depth positions. From an analysis of Figures 5 and 6 , area 1 was found to be located in the (6) mudstone layer. Due to the low elastic modulus of mudstone, which was not in the actual control range of the anchor bolts, this position was controlled only by part of the anchor cable. Therefore, the rock mass in this area was affected not only by the mining of the working face but also by the surrounding rock support of the roadway, which first caused the stress to change in this area and then 

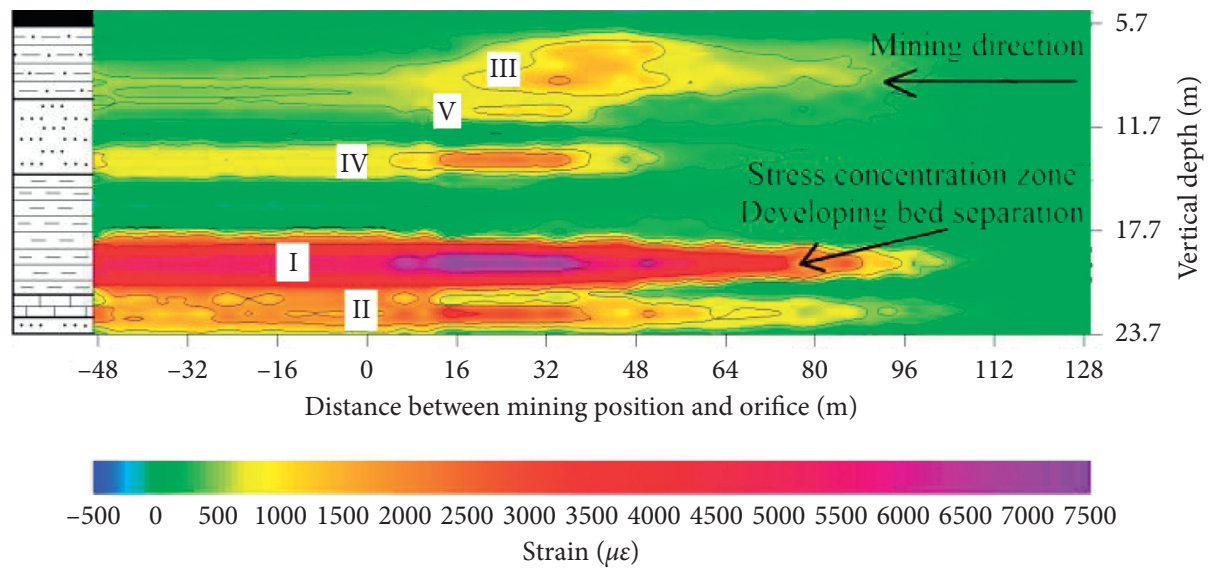

FIGURE 7: Fiber optic strain distribution nephogram during the monitoring period.

formed an area of concentrated stress. When the stress in the mudstone exceeded its bearing strength, the deformation and failure of the rock mass in this area could not be controlled and restrained effectively by the anchor cable. Finally, it ruptured, producing stratified cracks. In area II, however, which was also affected by many other factors, due to effective control by the anchor bolts, even though the internal strain in the surrounding rock that had a high elastic modulus changed substantially, it still did not cause structural failure of the rock mass, and the surrounding rock structure of the roadway as a whole remained relatively stable $[36,37]$. Areas III, V, and IV were only affected by mining, and so, the strain amplitude of the rock mass was relatively small.

4.2.2. Self-Potential Monitoring. Comparative analysis of Figures 8(a) and 8(b) shows that the self-potential varied considerably, both within and outside the range over which damage occurred. The current through each electrode in the destruction zone decreased slowly as mining of the working face continued during the monitoring period. When the propulsion distance of the working face exceeded $58.9 \mathrm{~m}$, the self-potential rose briefly and then dropped sharply, indicating that microcracks had sprouted in the rock mass. This was followed by a large fluctuation in the continuous steep rise and drop, with a maximum fluctuation of $600 \mathrm{~mA}$ (Figure 8(a)). When the rock mass was in a state of continuous damage, the development, penetration, and rupture of the microcracks alternated and coexisted and the selfpotential signal generally decreased and fluctuated in a pulse-like manner. Until the working surface advanced by a distance of approximately $163.6 \mathrm{~m}$, that is, until it exceeded the orifice of $34.42 \mathrm{~m}$, the whole structure was in a stable state. In this process, the overall trend of each electrode was clear and highly consistent. From Figure 8(b), it can be seen that there was no obvious fluctuation due to the absence of severe deformation and damage in the internal structure of the rock mass, and the data in this range were less consistent than the data shown in Figure 8(a). The above results are also consistent with the findings of researchers such as Liu et al.
[38] and Hao et al. [39]. These authors believed that the amplitude of the self-potential field anomaly caused by the crack tip discharge during rock rupture was much larger than that caused by rock deformation. Judging from the selfpotential measured by the electrodes at different depths in the borehole, the damage to the bottom plate was $0-20.7 \mathrm{~m}$ (electrodes \#1-26 were inside the destruction zone). The self-potential data were basically consistent with the depth of damage data, as measured by the fiber optics.

To further verify the above analysis, the electrode current data obtained during monitoring were processed into a cloud map (Figure 9). From this map, it can be seen that as mining neared the monitoring hole, the electrode current at the bottom plate at a depth of $0-20.5 \mathrm{~m}$ decreased overall, indicating that the rock mass in this range was deformed due to the difference in rock lithology. Therefore, there were differences in how much the electrode currents decreased in the various rock formations, and stratification was obvious. By comparison with Figure 7 , it can be seen that the electrode currents in areas I, III, IV, and V begin to decrease, and the corresponding fiber optic strain values begin to increase, which indicates that the rock mass in this area was damaged by stress and cracks; the strain value increased after the fiber optic was pulled, and the electrode current decreased because of the poor contact between the electrode and the rock mass. With the mining of the working face exceeding the orifice, the vertical depth of the floor was $0-20.5 \mathrm{~m}$ in the failure area, the electrode current increased, and the corresponding strain decreased due to the collapse of the overlying rock mass and the compression of the floor crack. In the process of mining, the electrode current in area I showed the largest decrease and the most obvious change in the value of strain, which was caused by the concentration of stress and the formation of separated layer cracks. Compared with the electrode current data gathered during the entire monitoring period, the electrode current in the upper part of the floor gas drainage roadway was increasing (area II). Although there was a certain amount of stress in the surrounding rock of the bottom extraction roadway, due to the anchoring effect of the anchor bolts, a 


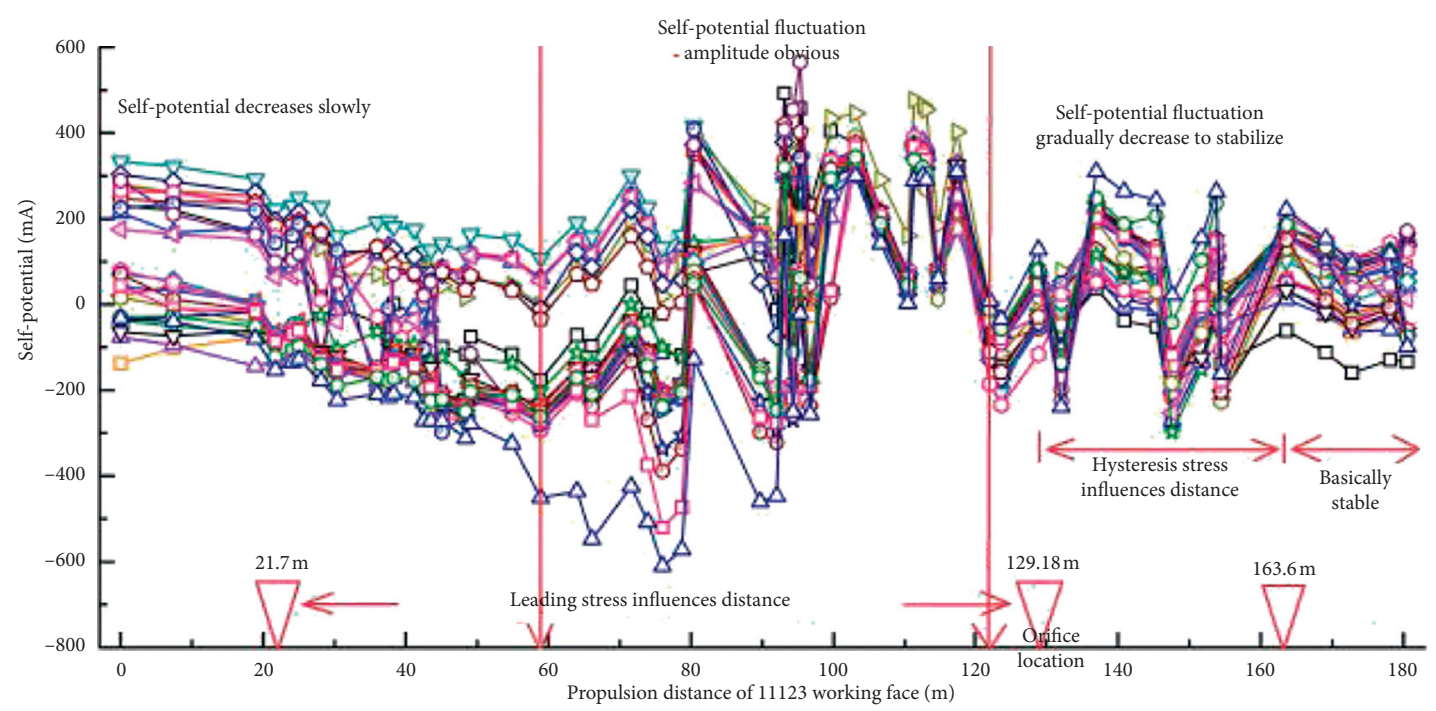

Electrode sequence number

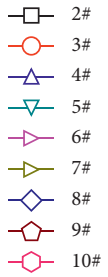

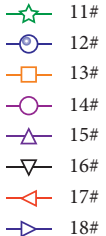

$\checkmark 19 \#$ -20 - 20 .

$-0-21 \#$

$\rightarrow 22 \#$

-○- 23\#

$-\square-24 \#$

$-\mathrm{O}-25 \#$

$\triangle-26 \#$

(a)

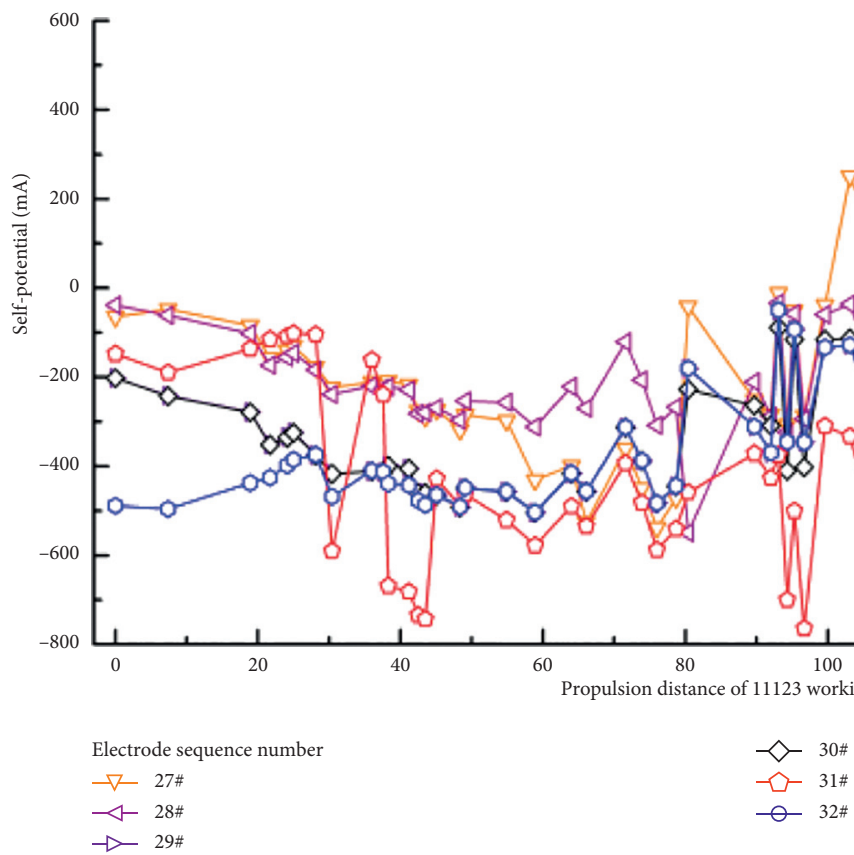

(b)

Figure 8: Self-potential curves at different depths.

composite rock beam with enhanced damage resistance and bearing capacity was formed, which was pulled on by the deep anchoring end of the surrounding rock of the roadway $[40,41]$. By limiting its degree of deformation and failure, the electrode current and strain in that region increased at the same time.
According to the monitoring data and the actual observations of field personnel, there were no fracture and collapse of the surrounding rock of the floor gas drainage roadway under the strong supports, and the entire floor gas drainage roadway remained relatively stable under dynamic pressure. 


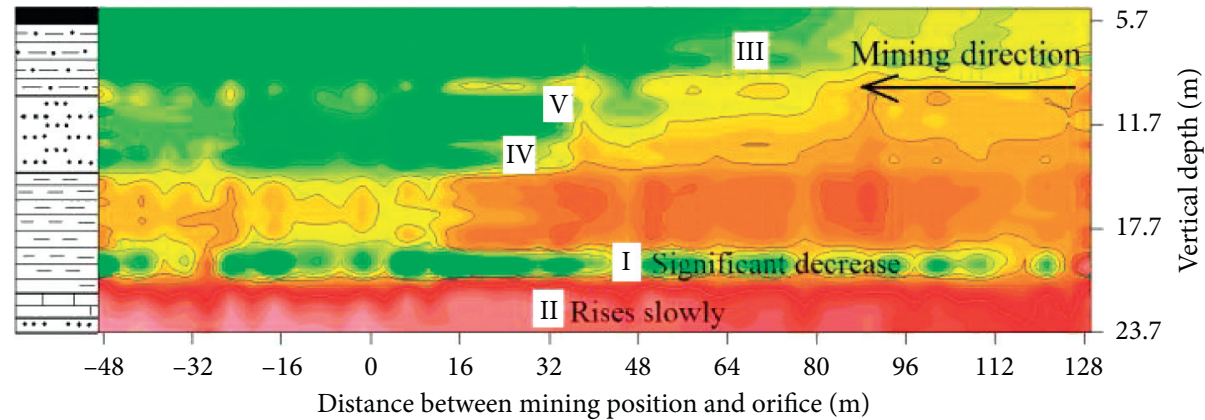

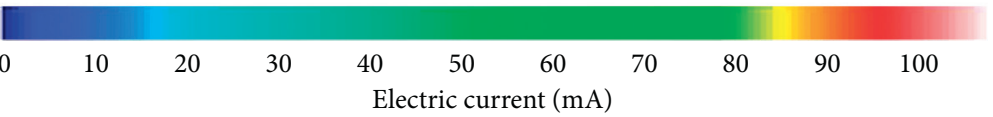

FIGURE 9: Nephogram of the changes in electrode current during monitoring.

4.2.3. Range of Effects of "Leading" and "Lagging" Stresses of the Working Face. Measurement points were selected at the fiber optic positions corresponding to the electrode positions on the cable in order to extract and process the data, which were combined with the natural potential and strain data in order to analyze the range of effects of the "leading" and "lagging" stresses of the working face (Figures 8 and $10)$.

By using natural potential exploration technology and BOTDR-distributed fiber optic testing technology, we were able to accurately measure and verify the deformation and failure characteristics as well as the evolution trend of the floor rock mass during the mining process of the 11123 working face. Our analysis shows that the mining distance of the 11123 working face of $21.7 \mathrm{~m}$ did no effect on the rock strata in the monitoring section. Until the mining distance was more than $21.7 \mathrm{~m}$, the leading stress did not affect the surrounding rock mass of the floor gas drainage roadway in the monitoring area and gradually formed the area of concentrated stress. The distance of the mining working face was within $58.9 \mathrm{~m}$, and there was no obvious fracture in or other damage to the rock floor. When the propulsion distance exceeded $58.9 \mathrm{~m}$, the self-potential of the rock mass in the failure zone of the floor plate had a cyclical fluctuating pattern of a steep rise followed by a steep drop, while the strain value increased rapidly at the same time. During this process, the floor rock mass produced cracks and rapidly developed into the deep. Until the mining face exceeded the orifice, the overlying rock mass collapsed to fill the goaf and transferred the stress to the floor rock mass, causing the expansion crack generated by the original tension to gradually shrink. When the working face mining distance exceeded $163.6 \mathrm{~m}$, the fluctuations in the self-potential and the strain data tended to be stable, indicating that the crack in the rock mass in the monitoring section shrank to reach its final degree of stability during this process.

According to this comprehensive analysis, we consider that the effect of the lead stress on the 11123 working face was $107.48 \mathrm{~m}$, and the range of effect of the lagging stress was $34.42 \mathrm{~m}$.
4.3. Variation in Multiparameter Data at Different Measurement Point Depths. By analyzing the strain, self-potential, and electrode current data, the failure of the floor under the influence of dynamic pressure and the stability of the surrounding rock mass of the floor gas drainage roadway are discussed. The floor failure depth of the 11123 working face was 0-20.7 m (electrodes \#1-26 were located in it), and the surrounding rock structure of the floor gas drainage roadway was relatively stable (electrodes \#27-32 were located in it). Further analysis of the variation in and relationship of the multiparameter data at different depths under the influence of dynamic pressure reveals the differences in dynamic evolution and the mechanism of changes in the rock mass of the destruction zone and the floor gas drainage roadway during the mining process. We selected six groups of data from different measurement point depths for analysis (Figure 11).

The changes in data at each measurement point located within the damage range of the floor (Figures 11(a)-11(d)) were observed. In the early stage of coal mining, the values of the self-potential data obtained at each measurement point gradually decreased by approximately $250 \mathrm{mV}$. The overall decrease in amplitude of the electrode current was not obvious and was approximately $3 \mathrm{~mA}$ only. However, the strain at each measuring point increased, but the range of values was different because of the different rock lithologies.

When the mining distance of the working face exceeded $58.9 \mathrm{~m}$, the data collected from different measurement point depths changed gradually and by a significant amount. The self-potential fluctuated considerably, with a maximum amplitude of $400 \mathrm{mV}$, and then the fluctuation weakened before it finally stabilized. The electrode current, in contrast, showed a rapid decrease. This process continued until the working surface mining distance reached $118 \mathrm{~m}$, and the electrode current value dropped by $18 \mathrm{~mA}$. By this stage, the mining position had crossed the measuring point by approximately $26 \mathrm{~m}$. Subsequently, the current value climbed quickly to $73 \mathrm{~mA}$ until the late monitoring period, while the current value slowly decreased and eventually stabilized at $68 \mathrm{~mA}$. The strain value rose rapidly and then slowly decreased (Figure 11(a)). 


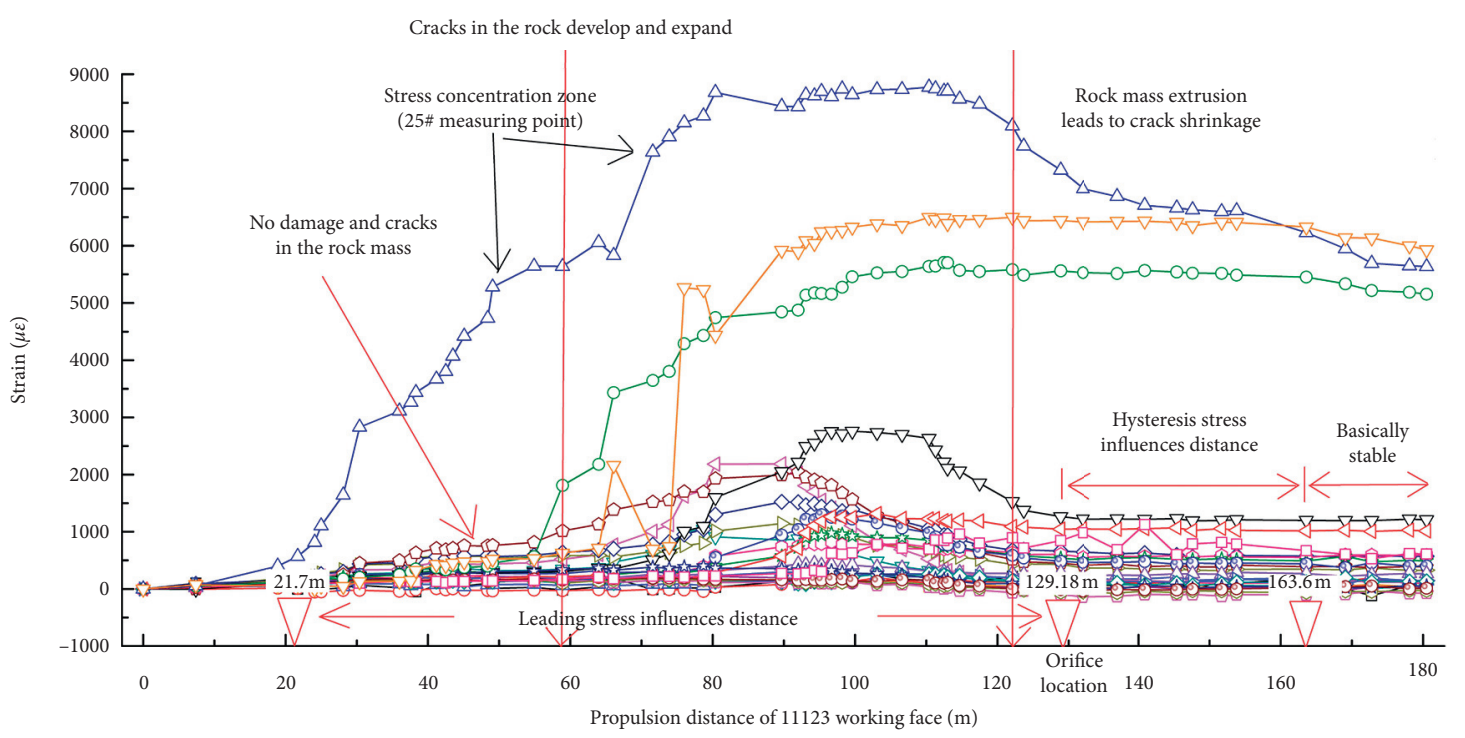

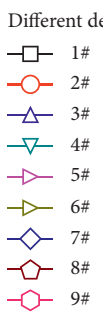

牙 10\#

-○- 11\#

$-\square-12 \#$

-O- 13\#

$-\triangle-14 \#$

$\rightarrow-15 \#$

$\triangleleft 16 \#$

$\rightarrow 17 \#$

$\checkmark 18 \#$

(a)
- 19 19

- 20 -

- 21 元

-Оㄴ 22\#

$-\square-23 \#$

- -24 - 24

$\triangle-25$

$-\nabla-26 \#$

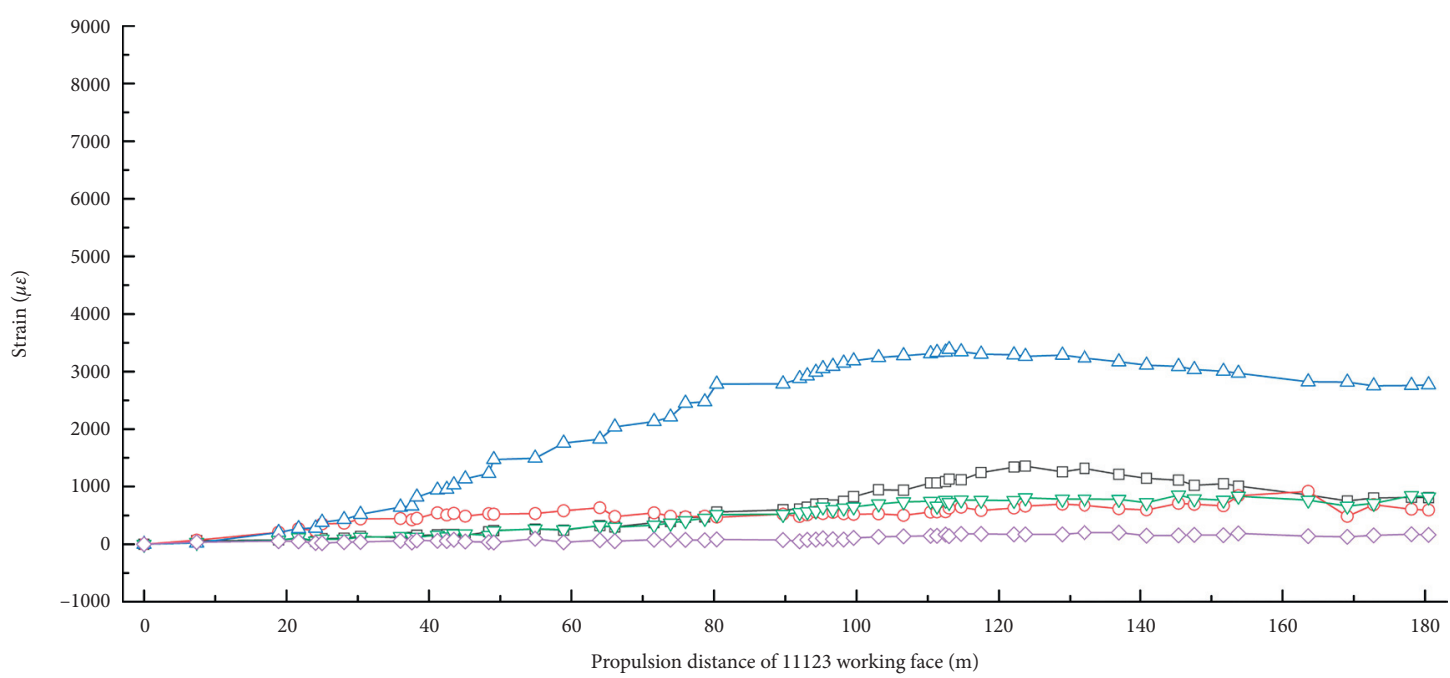

Different dep
$-\square-28 \#$
$-\bigcirc-29 \#$
$-\square \quad 30 \#$
$-\nabla-31 \#$
$\square-32 \#$

(b)

Figure 10: Variation of strain with advancing distance.

The values obtained for the measurement points at depths of 9.18 and $13.45 \mathrm{~m}$ were similar. Affected by mining, the self-potential in the rock also showed large fluctuations, and the maximum fluctuation was approximately $550 \mathrm{mV}$.
The decrease in electrode current in this depth range was small, at approximately $10 \mathrm{~mA}$. Subsequently, there was only a small increase before a steady state was reached. The strain value rose rapidly and then fell (Figures 11(b) and 11(c)). 


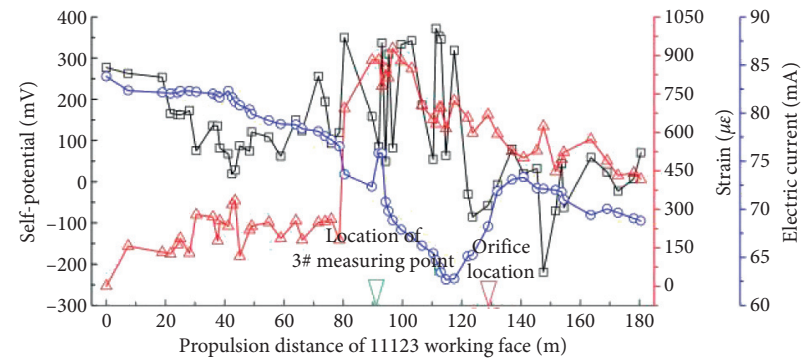

(a)

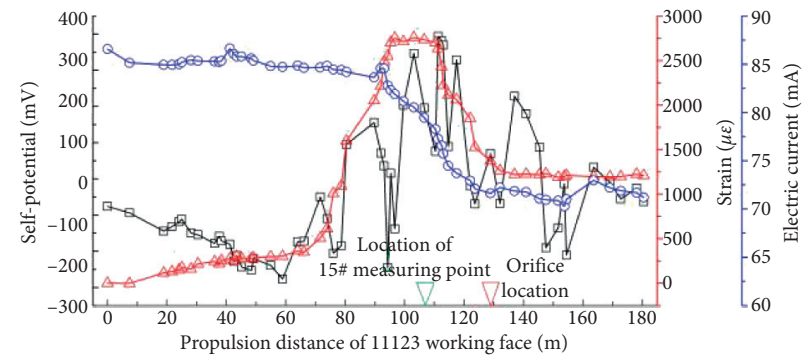

(c)

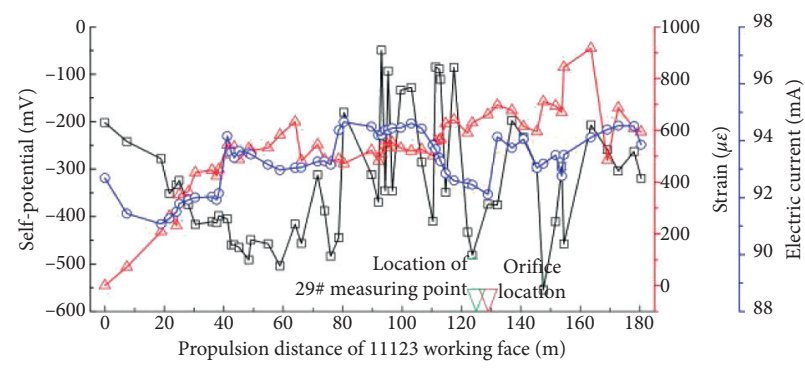

(e)

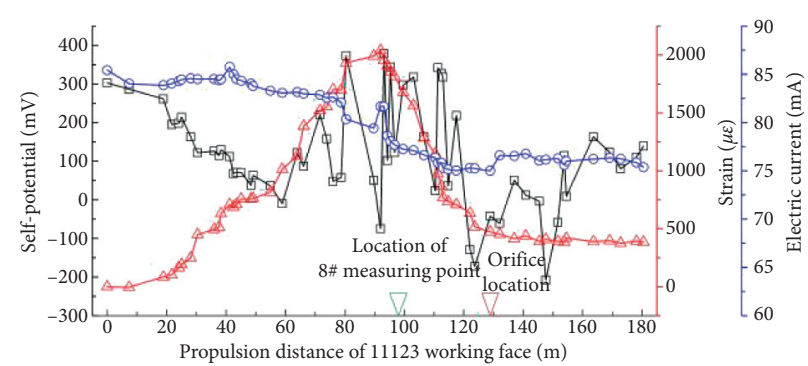

(b)

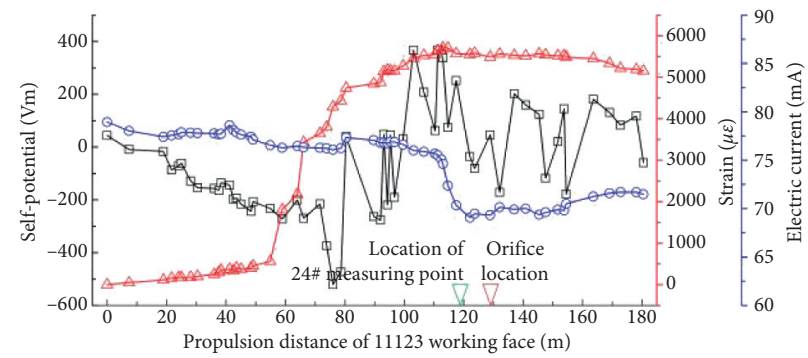

(d)

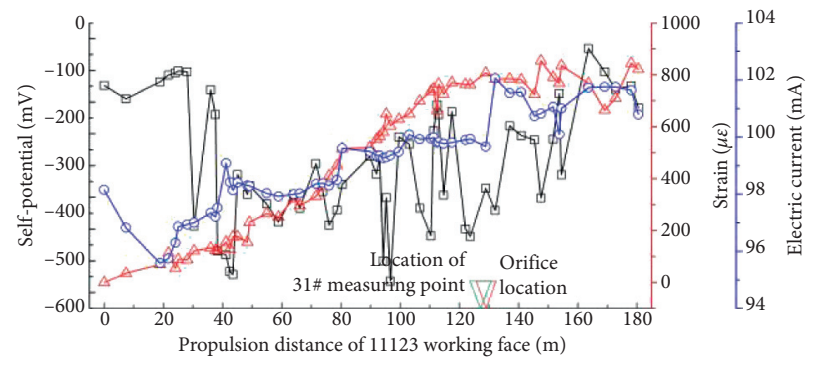

(f)

Figure 11: Multiparameter variation in the data obtained at different measuring point depths: (a) $6.13 \mathrm{~m}$; (b) $9.18 \mathrm{~m}$; (c) $13.45 \mathrm{~m}$; (d) $18.94 \mathrm{~m}$; (e) $22.6 \mathrm{~m}$; (f) $23.21 \mathrm{~m}$.

The \#24 measurement point was located in the stress concentration area under the base plate, and the maximum value was $5800 \mu \varepsilon$. The strain value decreased only slightly and finally stabilized at $5100 \mu \varepsilon$ (Figure 11(d)). The change in amplitude of the same parameter at different measurement point depths was different, which was affected mainly by the differences in the rock lithology and the depth from the floor.

Under the influence of dynamic pressure, the deformation and failure of the rock mass in the range of floor failure were violent and obvious, and the dynamic changes in the self-potential, electrode current, and strain value were captured effectively at each measurement point depth. It should be noted that there were significant differences between the electrode currents obtained at the \#3 measuring points close to the bottom plate and those obtained at the other positions. It is believed that the cracks in the rock mass were still developing and penetrating as the mining position exceeded the upper part of the measuring point. During this period, the compressive stress induced by the collapse of the overlying rock mass was not transmitted to the bottom slate layer, so that the electrode current was significantly reduced. When the mining distance of the working face exceeded
$118 \mathrm{~m}$, the electrode current stopped falling and then rose rapidly. This phenomenon shows that the stress in the overlying rock mass could be transferred effectively to the bottom plate when this happened, and this process took eight days to complete. From this, we infer that, after mining, there is a process of secondary failure and deepening in the floor rock mass. After a period of time, the downward stress of the overlying collapsed rock mass can be completely transferred to the floor, making the cracks in the shallow rock mass of the floor squeeze or close until the floor is finally stable, and this process can last for eight days or potentially longer. Therefore, attention should not only be paid to the deformation and failure of the floor rock mass in front of the mining but the failure of the floor rock mass behind the mining should also continue to be monitored.

Finally, we observed the changes in the parameters captured at two measuring points near the surrounding rock mass of the floor gas drainage roadway and then analyzed and determined the stability of the surrounding rock mass (Figures 11(e) and 11(f)). In contrast to the above four data plots, there were significant differences in the data presented in Figures 11(e) and 11(f). It is clear that the electrode currents obtained from these two measuring points do not 
show a slow decrease, then a significant decrease, followed by an increase. In contrast, the electrode current shows a step-by-step rising phenomenon. It should be noted that each increase in electrode current is followed by a small decrease. We believe this to be a dynamic self-adjustment process of concentration and release of the stress in the surrounding rock under the joint action of working face mining and the roadway support structure. The existence of this process is an important indicator of the stability of the surrounding rock structure of the floor gas drainage roadway. In addition, the strain value during the entire monitoring period showed a slow rising trend, which finally stabilized, and this process was basically controlled within $1000 \mu \varepsilon$. Combined with the natural potential data, it can be shown that the whole process fluctuated continuously within a certain range, which was different from the changes in the previous four measurement points.

\section{Discussions}

Based on the method using comprehensive monitoring of BOTDR-distributed fiber optics and spontaneous potential exploration, the floor failure characteristics and bottom extraction roadway stability of the 11123 working face of a coal mine in Huainan, Anhui Province, China were studied. The variations in the multiparameter data obtained at different depth measurement points were analyzed.

In summary, we find that the changes in the various parameters of rock formation under the influence of dynamic pressure are obvious and can reflect the deformation and failure process of the rock mass at different depths of the bottom plate. There are still some differences between the different depth measurement points in the failure range due to the different lithologies of the rock strata and their location relative to the floor. In the wake of coal mining, there is a process of secondary failure and deepening of the floor rock mass in the goaf. After a period of time, the downward stress of the overlying collapsed rock mass can be fully transmitted to the floor, making the cracks in the shallow rock mass of the floor squeeze or close until the floor is finally stable, and this process lasts approximately for eight days. The electrode current in the surrounding rock of the floor gas drainage roadway showed a step-by-step rising phenomenon. It should be noted that each increase in the electrode current was followed by a small decrease. We believe that this is a dynamic self-adjustment process of the concentration and release of the stress in the surrounding rock under the joint action of working face mining and the roadway support structure. The existence of this process is an important indicator of the stability of the surrounding rock structure of the floor gas drainage roadway.

Under the influence of dynamic pressure, the rock mass will be deformed or even damaged macroscopically. Before the macroscopic change, the microcosmic complex dynamic process of physical and chemical fields will be formed in the rock mass. It is difficult to effectively capture the information in this stage by conventional testing methods (pressure gauge, displacement gauge, borehole TV, etc.) $[5,42]$. The comprehensive monitoring technology adopted in this study can capture the change information of physical and chemical fields of rock mass at macro- and microlevels $[8,12,29,30,34,38]$. Coal mining changes the original stress field distribution in the rock body:

(1) In the stage of rock elastic deformation, the change of stress field in rock mass is not obvious, but the distributed strain sensing optical fiber can capture the strain change greater than $25 \mu \varepsilon$ and can reflect the compression or tension stress of rock mass $[12,30,31]$. In addition, there are a large number of primary microcracks in the deep rock mass under the natural state. The increase and decrease of the stress change rate in the rock mass will cause the change of the distance between the microcharges and then cause the change of the density of the polarization charge in the rock mass, forming the polarization current, resulting in the movement of the free charge and the change of the natural potential $[34,35,38]$.

(2) With the increase of mining stress field, the rock mass will have obvious deformation, the rock porosity will also change, and the primary or secondary microcracks will increase and expand. The distributed strain sensing optical fiber and spontaneous potential exploration can capture the macroscopic and microscopic structural change characteristics of rock mass in the whole process of stress [12, 30, 38]. Once the load of rock mass exceeds its bearing limit, microcracks will connect with each other and produce macro cracks, that is, rock mass fracture and instability. In this process, a large number of free electrons leave the fracture area of rock mass instantaneously, resulting in electrical property mutation. When the rock mass is in a continuous damage state, the spontaneous potential will form a pulse-like fluctuation. During this period, the deformation and failure state of the rock mass can also be captured by distributed strain sensing optical fiber $[35,38,39]$. In addition, if there is fracture water flow in the rock mass, the distribution range and flow situation of the water body can be mastered by means of electrical prospecting technology such as spontaneous potential [43].

The multifield monitoring method has the following advantages compared with the conventional testing methods: (1) the conventional test methods usually use a single-test method, usually from the macromeasurement of the movement and deformation of rock mass, the development and fracture of rock mass, etc. Our research can capture the response characteristics and change rules of multifield data caused by deformation and damage of rock mass in the process of mining from macro- and microperspectives. Also, different sensors have their own advantages. The results obtained by comparative analysis of various data are more reliable. (2) The conventional test methods are mostly point acquisition, with less measurement data and shorter sensor survival time, so it is difficult to continuously obtain the data after the working face mining exceeds the measurement point. In this study, the sensor has 
the advantages of strong anti-interference, high survivability, more data points, and large amount of data. It can completely capture the multifield data information of rock mass damage change in each stage of mining.

In this study, multiphysical field monitoring technology is applied to monitor the stability of roadway surrounding rock. In addition, this set of multifield monitoring system can also be applied to the monitoring of roof and floor rock deformation failure, protection of coal pillar stability, and other related monitoring.

\section{Conclusions}

(1) The extent of damage to the working face was concentrated mainly in the upper mudstone layer of the top anchor of the floor gas drainage roadway, and the depth of damage was approximately $20.7 \mathrm{~m}$. The overall stability of the surrounding rock mass structure of the floor gas drainage roadway was good.

(2) The influence of mining pressure on the bottom plate had the characteristics of "advance" and "lag" continuation over long distances. Of these, the range of effect of the leading support stress of the 11123 working face was $107.48 \mathrm{~m}$ and that of the lagging stress was $34.42 \mathrm{~m}$.

(3) Under the influence of dynamic pressure, the evolution of floor cracks showed spatiotemporal characteristics. In the wake of coal mining, there is a process of secondary failure and deepening of the floor rock mass in the goaf. After a period of time, the downward stress of the overlying collapsed rock mass can be fully transmitted to the floor, making the cracks in the shallow rock mass of the floor squeeze or close until the floor is finally stable, and this process lasts approximately for eight days.

(4) By installing a fiber optic cable and an electric cable monitoring system in the monitoring hole, the process of damage to the bottom plate was completely captured. A comprehensive technical evaluation system with multiple physical fields and parameters was designed and implemented. The results of this study can provide guidance for devising suitable procedures, for carrying out intelligent green safety mining, and for warning about the hazards of roadway damage.

The limitations of this study and the future direction of this work are as follows: (1) only one monitoring hole is designed on-site, and the data obtained can only objectively reflect the actual situation of the area. Therefore, in the later research work, it is necessary to design multiple monitoring boreholes in different directions in the surrounding rock of roadway, so as to obtain comprehensive and multiangle deformation and failure of surrounding rock; (2) in the study, the monitoring method of multiple physical fields is used to obtain a large number of reliable data, but it still needs to be compared with some traditional verification methods. In the later research, we need to further strengthen the relevant verification and comparison work; and (3) at present, the field monitoring work generally relies on the underground data collection of researchers, and the degree of intelligent collection is not high. In the future, the underground sensor monitoring system needs to be connected to the ground remote automatic monitoring and early warning platform through $5 \mathrm{G}$ network technology to realize unmanned, automatic, intelligent and integrated data acquisition, processing and analysis, forecasting, and early warning.

\section{Data Availability}

The data used to support the findings of this study are available from the corresponding author upon request.

\section{Conflicts of Interest}

The authors declare that there are no conflicts of interest regarding the publication of this paper.

\section{Acknowledgments}

This research work was supported by the National Natural Science Foundation of China (Grant nos. 41877268 and 41702177), the Key R\&D Program Projects in Anhui Province (Grant no. 1804a0802213), and the Graduate Innovation Fund Project of the Anhui University of Science and Technology (Grant no. 2019CX1002), which are gratefully acknowledged.

\section{References}

[1] L. Yuan, "Scientific problem and countermeasure for precision mining of coal and associated resources," Journal of China Coal Society, vol. 44, no. 1, pp. 1-9, 2019.

[2] Y. G. Li, N. J. Ma, J. Ma, H. Zhang, and Z. Gao, "Surrounding rock's failure characteristic and rational location of floor gas drainage roadway above deep confined water," Journal of China Coal Society, vol. 43, no. 9, pp. 2491-2500, 2018.

[3] S. Mo, P. Sheffield, and P. Corbett, "A numerical investigation into floor buckling mechanisms in underground coal mine roadways," Tunnelling and Underground Space Technology, vol. 103, Article ID 103497, 2020.

[4] J. B. Wei, S. M. Wang, Z. Zhao, D. L. Li, and L. P. Guo, "Numerical study of damage to rock surrounding an underground coal roadway excavation," Advances in Civil Engineering, vol. 2020, Article ID 8863289, 16 pages, 2020.

[5] Y. Yuan, W. J. Wang, S. Q. Li, and Y. J. Zhu, "Failure mechanism for surrounding rock of deep circular roadway in coal mine based on mining-induced plastic zone," Advances in Civil Engineering, vol. 2018, Article ID 1835381, 14 pages, 2018.

[6] L. Q. Shi and J. Han, "Theory and practice of dividing coal mining area floor into four-zone," Journal of China University of Mining and Technology, vol. 34, no. 1, pp. 17-23, 2005.

[7] M. G. Qian, X. X. Miao, and L. J. Li, "MeChalism for the fracture behaviours of main floor in longwall mining," Chinese Jounral of Goetechnical Engineering, vol. 17, no. 6, pp. 55-62, 1995.

[8] Y. Ou, P. Zhang, and W. Wang, "Study on the evolution rule of land damage based on electrical resistivity imaging 
technology in mining face," Geotechnical and Geological Engineering, vol. 37, no. 5, pp. 4259-4268, 2019.

[9] M. C. He, H. P. Xie, S. P. Peng, and Y. D. Jiang, "Study on rock mechanics in deep mining engineering," Chinese Journal of Rock Mechanics and Engineering, vol. 24, no. 16, pp. 28032813, 2005.

[10] Q. Wu, B. Li, S. Q. Liu, and Y. F. Zeng, "Vulnerability assessment of coal floor groundwater bursting based on zoning variable weight model: a case study in the typical mining region of Kailuan," Journal of China Coal Society, vol. 38, no. 9, pp. 1516-1521, 2013.

[11] P. L. Su and Z. F. Wei, "Depth of floor failure of stope with medium-thickness coal seam," Geotechnical and Geological Engineering, vol. 36, no. 2, pp. 1341-1347, 2018.

[12] P. Zhang, Y. Ou, B. Sun, and C. Liu, "A case study of floor failure characteristics under fully mechanised caving mining conditions in extra-thick coal seams," Journal of Geophysics and Engineering, vol. 17, no. 5, pp. 813-826, 2020.

[13] W. C. Song, Z. Z. Liang, and C. B. Zhao, "Mechanical failure characteristics of mining floor along working face inclination above confined water," Chinese Journal of Rock Mechanics and Engineering, vol. 37, no. 9, pp. 144-156, 2018.

[14] P. S. Zhang, J. W. Wu, and S. D. Liu, "Study on dynamic observation of coal seam floor failure law," Chinese Journal of Rock Mechanics and Engineering, vol. 25, no. s1, pp. 30093013, 2006.

[15] R. Zhang, Z. Q. Jiang, Z. C. Yue, L. T. Zhao, and X. L. Yu, "InSitu dynamic observation and numerical analysis of thick coal seam floor's failure law under the mining," Journal of Mining \& Safety Engineering, vol. 29, no. 5, pp. 625-630, 2012.

[16] S. Y. Zhu, D. T. Cao, H. Y. Zhou, C. W. Yang, and J. G. Liu, "Restrictive function of lithology and its composite structure on deformation and failure depth of mining coal seam floor," Journal of Mining \& Safety Engineering, vol. 31, no. 1, pp. 90-96, 2014.

[17] H. P. Kang, G. F. Wang, P. F. Jiang et al., "Conception for strata control and intelligent mining technology in deep coal mines with depth more than $1000 \mathrm{~m}$," Journal of China Coal Society, vol. 43, no. 7, pp. 1789-1800, 2018.

[18] X. Y. Wu, J. Y. Wang, W. C. Wang, C. Tian, Q. W. Bu, and $\mathrm{L}$. Wu, "Study on the stage failure mechanism and stability control of surrounding rock of repeated mining roadway," Advances in Civil Engineering, vol. 2020, Article ID 8866559, 16 pages, 2020.

[19] X. L. Zhang, H. A. Nguyen, X. N. Bui et al., "Evaluating and predicting the stability of roadways in tunnelling and underground space using artificial neural network-based particle swarm optimization," Tunnelling and Underground Space Technology, vol. 103, Article ID 103517, 2020.

[20] J. Wang, Z. Guo, Y. Yan, J. Pang, and S. Zhao, "Floor heave in the west wing track haulage roadway of the Tingnan coal mine: mechanism and control," International Journal of Mining Science and Technology, vol. 22, no. 3, pp. 295-299, 2012.

[21] M. G. Qian, P. W. Shi, and J. L. Xu, Mine Pressure and Rock Formation Control, China University of Mining and Technology Press, Xuzhou, China, 2010.

[22] C. J. Hou, "Effective approach for surrounding rock control in deep roadway," Journal of China University of Mining \& Technology, vol. 46, no. 3, pp. 467-473, 2017.

[23] H. Yavuz, "An estimation method for cover pressure re-establishment distance and pressure distribution in the goaf of longwall coal mines," International Journal of Rock Mechanics and Mining Sciences, vol. 41, no. 2, pp. 193-205, 2004.
[24] B. Duan, H. Xia, and X. Yang, "Impacts of bench blasting vibration on the stability of the surrounding rock masses of roadways," Tunnelling and Underground Space Technology, vol. 71, pp. 605-622, 2018.

[25] G. C. Li, Z. Q. Ma, N. Zhang, P. P. Wang, and R. Ma, "Research on failure characteristics and control measures of roadways affected by multiple overhead mining in Huaibei mining area," Journal of Mining \& Safety Engineering, vol. 30, no. 2, pp. 181-187, 2013.

[26] D. H. Chen, X. Z. Hua, Y. W. Duan, and S. X. Cheng, "Simulation of zonal tensile and compressive deformation and failure of surrounding rock in deep large deformation mining gateway," Rock and Soil Mechanics, vol. 37, no. 9, pp. 26542662, 2016.

[27] X. Z. Hua and P. Yang, "Floor deformation dynamic evolution of gobside entry retaining with large section in deep mine," Journal of China University of Mining \& Technology, vol. 47, no. 3, pp. 39-46, 2018.

[28] S. C. Li, L. Wang, B. Jiang, Q. Wang, H. J. Zhang, and B. H. Liu, "Microseismic characteristic and failure mechanism of roadway below coal pillar under dynamic pressure," Journal of China University of Mining \& Technology, vol. 48, no. 2, pp. 247-257, 2019.

[29] D. Zhang, P. S. Zhang, B. Shi, H. X. Wang, and C. S. Li, "Monitoring and analysis of overburden deformation and failure using distributed fiber optic sensing," Chinese Journal of Geotechnical Engineering, vol. 37, no. 5, pp. 952-957, 2015.

[30] S. A. Xu, S. M. Wang, P. S. Zhang, D. X. Yang, and B. Y. Sun, "Study on strain characterization and failure location of rock fracture process using distributed optical fiber under uniaxial compression," Sensors, vol. 20, no. 14, p. 3853, 2020.

[31] J. Chai, Z. W. Xue, R. Guo, D. D. Zhang, Q. Yuan, and Y. Li, "Experimental study of overlying mine strata collapse and its evolution by a distributed optical fiber system," Journal of China University of Mining \& Technology, vol. 47, no. 6, pp. 32-39, 2018.

[32] P. S. Zhang and S. A. Xu, "Development and application of mine fiber testing technology," Progress in Geophysics, vol. 31, no. 3, pp. 1381-1389, 2016.

[33] S. D. Liu and P. S. Zhang, "Distributed parallel intelligent electrode potential difference signal acquisition method and system," Chinese Invention Patent: ZL200410014020.0, 2005.

[34] E. Y. Wang, Z. H. Li, Z. T. Liu, Y. N. Li, and X. Y. Song, "Expermental study on surface potential effect of coal under load," Chinese Journal of Geophysics, vol. 52, no. 5, pp. 1318-1325, 2009.

[35] X. Y. Song, Z. H. Li, and E. Y. Wang, "Charging characteristics of the crack propagation of rock under load," Journal of China Coal Society, vol. 41, no. 8, pp. 1941-1945, 2016.

[36] H. P. Kang, J. Lin, and M. J. Fan, "Investigation on support pattern of a coal mine roadway within soft rocks-a case study," International Journal of Coal Geology, vol. 140, pp. 31-40, 2015.

[37] J. C. Chang, D. Li, T. F. Xie, W. B. Shi, and K. He, "Deformation and failure characteristics and control technology of roadway surrounding rock in deep coal mines," Geofluids, vol. 2020, Article ID 8834347, 15 pages, 2020.

[38] J. Liu, S. D. Liu, and Y. Cao, "Self-potential characteristics in deep rock mass damage based on point discharge mechanism," Chinese Journal of Geophysics, vol. 61, no. 1, pp. 323-330, 2018.

[39] J.-Q. Hao, L.-Q. Liu, H.-L. Long et al., "New result of the experiment on self-potential change of rocks under biaxial 
compression," Chinese Journal of Geophysics, vol. 47, no. 3, pp. 539-547, 2004.

[40] P. H. S. W. Kulatilake, Q. Wu, Z. Yu, and F. Jiang, "Investigation of stability of a tunnel in a deep coal mine in China," International Journal of Mining Science and Technology, vol. 23, no. 4, pp. 579-589, 2013.

[41] Z. L. Su, W. B. Xie, S. G. Jing, X. K. Wang, and Q. T. Tang, "Fracturing of the soft rock surrounding a roadway subjected to mining at kouzidong coal mine," Advances in Civil Engineering, vol. 2020, Article ID 6858643, 17 pages, 2020.

[42] H. S. Jia, K. Pan, S. W. Liu, B. Peng, and K. Fan, "Evaluation of the mechanical instability of mining roadway overburden: research and applications," Energies, vol. 12, no. 22, p. 4265, 2019.

[43] S. D. Liu, J. Liu, J. Qi, Y. Cao, and R. Q. Lv, "Applied technologies and new advances of parallel electrical method in mining geophysics," Journal of China Coal Society, vol. 44, no. 8, pp. 2336-2345, 2019. 